\title{
An Experimental Access of Spiral Plate Heat Exchange Technique in Immiscible Liquid Mixtures
}

\author{
Bhanu Pratap Pulla, G .R .Selokar
}

\begin{abstract}
From past decades, energy saving has been a significant process, so countless manufacturing firms are utilizing heat exchanger (HE) for lessening energy consumption; thereby diminishing the fuel expenses. Obviously, 'HE' stands as the most critical segment for the chemical response, refining, disintegration, crystallization, aging and so forth. Here, the liquid-liquid (LL) 2-phase heat transfer contemplates were directed on a spiral plates heat exchanger (SPHE) with water as the hot fluid (HF), and octane, kerosene, dodecane, diesel, and nitrobenzene in various masses as the cold fluid (CF). Spiral plate type-HE process comprises ascertaining numerous heat transfer (HT) and also flow variables. The distance betwixt the sheets is ought to be constant to uphold the cross-sectional region throughout the spiral path of the channels. For every composition, the CF's mass flow rate was changed by keeping the $\mathrm{HF}$ and fluid inlet temperature $\left(T_{i n}\right)$ rates steady. $\mathrm{HF}$ coefficients (HTC) based on predictive experiential correlations were also analyzed for Nusselt Number from experimental information by linear Mixing Rule and also by linear regression. The results attained aimed at the fluid flows together with HT provide an idea concerning how the fluids' flow rate (FR) could be optimized, thereby, elevating the HE's efficiency.
\end{abstract}

Key words: Spiral Plate Heat Exchanger, Octane, Kerosene, Dodecane, Diesel, Nitrobenzene, Mass flow, Heat Transfer Coefficients.

\section{INTRODUCTION}

With the elevation in the temperature of the earth and fossil fuels costs in the $20^{\text {th }}$ centinum, the concern of lessening the energy expenditure has turned out to be significant. So, researchers have given more care to energy management. HE is amongst the cases wherein energy efficiency is vital. It stands as a tool utilized to transfer optimum heat as of a surrounding to a different one. 'HE' transmits heat betwixt ' 2 ' or more fluid streams flowing into it. This is utilized extensively in industries, for instance, heat recovery refrigeration, power plant, air conditioning, as well as manufacturing industries. Disparate sorts of heater condensers, boilers, regenerators, along with cooling towers are previously in use. In the processing industry, ' 2 ' -phase flow converters could i) evaporate, ii) distill along with iii) freeze a crystal, additionally, utilized as a fluidized bed encompassing some catalytic reactions [1]. This is employed for the transport of energy (thermal) as of ' 1 ' media to a different one on any physical state. Furthermore, Spiral heat

Revised Manuscript Received on September 10, 2019.

Bhanu Pratap Pulla, Bhanu Pratap Pulla, Scholar, Department of Mechanical Engineering, Sri Satya Sai University of Technology \& Medical Sciences - Sehore, M.P, India.

(Email id: pullabhanu@gmail.com)

Dr. G .R .Selokar, Professor and Registrar, Sri Satya Sai University of Technology \& Medical Sciences - Sehore, M.P, India.

(Email id: selokar1960dr@gmail.com) exchangers (SHE) were initially commenced in the nineteenth centenary. It is a perfect kind aimed at cooling slurries along with fluids with higher viscosity. This kind is extremely common in the paper, food along with petrochemical industries. SHEs can attain higher convective HT rates owing to the spiral patterns which retain the turbulent flow [2]. The circulating water-HE is extensively used for exchanging heat in contemporary petro-chemical enterprises as well as accounts for forty percent of the total investment in facilities [3].

In current years, immiscible liquid dissolution is gauged in effect. It largely concentrates on the approximations intended for dissolving multi-component liquids. The relevance also was highlighted aimed at LL extraction processes intended for chemical scrutiny. Numerous industrial procedures manufacture lower-grade heat that is repudiated owing to the short of thermal input requirements and because of upper-limits in a system's operating temperatures. In current times, thermo-electric power generation as of the thermal energy transferred in a working fluid has garnered attention [4][5]. Obviously, much attention is concentrated on lessening these losses to ameliorate the operating efficiencies. Present research on thermo-electricity could well be roughly split into 2 classes: i) material and ii) application research. Former one is chiefly for generating new, more effectual, cheap, or more effortlessly constructed thermo-electric materials [6]. 'HE' has several industrial along with domestic applications. Nevertheless, the environmentalist's argument has brought about the researchers to concentrate more on the energyeffectual model of 'HE' to lessen their carbon foot-prints. The HT improvement is either attained via varying flow properties or geometric configuration. Consequently, the utilization of nanofluids exhibits to be a rising trend aimed at effectual thermal's performance. Nano-fluids are liquids encompassing suspended solids nano-sized metallic particles [7]. As a noteworthy part of the thermal systems, it is extensively employed in a array of industries. This is utilized for the effectual HT betwixt ' 2 ' (or more) working fluids as of one to a different one. Amongst a variety of sort of 'HE' present, 'SHE' has attained a significant seat in its industry. Their utilization is perfect for the cooling slurries along with viscous fluids. It could attain higher convective HT rates on account of the spiral pattern that uphold turbulent flow [8].

While manufacturing the cryogenic temperatures on the gas processing as well as petro-chemical industries, 
transport of thermal energy frequently happen amongst more than ' 3 ' streams or fluids. 3-fluid-HE, comprising of the ' 3 ' fluids on thermal communication, are employed in a variety of applications. A 3-fluid-HE with ' 2 ' thermal communications is examined aimed at its dynamic reaction to a step change on the $\mathrm{T}_{\text {in }}$ of the HF as well as CFs. The retort is examined aimed at its impact on the fluids' outlet temperatures $\left(\mathrm{T}_{\text {out }}\right)$, temperature profiles and as well the $\mathrm{HF}$ efficacy [9]. There are disparate sorts of 'HE' such as (i) recuperative, (ii) regenerative, and (iii) evaporative sort. In the $1^{\text {st }}$ sort, the fluid swap heat on sides of the separating wall. Additionally, the recuperative-HE might be designed to perform in disparate modes like (i) parallel flow, (ii) counter-flow, together with (iii) cross flow. This configuration signifies the flow direction of ' 2 ' liquids [10]. The SPHE model, specially the inner structure is split in to micro-volume, as well as energy balance. As they can well be employed to intensify heat exchange and have several advantages. Explicitly, very low power expenditure, practically un-limited operation life, the capability to operate on micro-gravity, and higher efficiency. This can well be a suitable supposition for mixtures of totally miscible and also correspondingly sized molecules [11][12][13]. Consequently, sophisticated cooling technology is needed and moreover, it has gained the curiosity of numerous researchers. [14].

To trounce the issues, new SPHE is proposed for immiscible liquid mixture. The residual sections are: Section 2 explored the related works concerning the technique proposed; sections 3 a concisely discusses the proposed methodology; section 4 explored the experiential outcome; lastly, section 5 deduces the paper.

\section{LITERATURE REVIEW}

Manabu Aoki [15], examined the 'HE' structure aimed at the solid nitrogen (N2) heat capacitors that slowed down the warming ratio of the super-conducting magnets amid a power malfunction. For enhancing the solid N2 transient heat transfer, it encompassed vertically layered structures for restricting the solid N2 thickness. Horizontally broad HT fins upheld thermal contact utilizing the solid N2 weight. The 'HE' solidified two-thousand cubic $\mathrm{cm}$ of liquid nitrogen in 60 minutes and frozen the HTS coil to an operating temperature by utilizing merely the cryocooler. In a temperature increase experimentation that closed the cryocooler about 60 minutes, it was evaluated that it utilized 28.3-35.1 (in percentage) heat capability of the solid N2.

Mehdi Bahiraei et al [16], suggested a countercurrent SHE for thermal as well as hydraulic traits of an ecofriendly graphene nano-fluid flowing. The cold water flowed on '1' side whilst the hot nano-fluid or else hot base fluid moved on the different side. The HT rate and overall HTC enhanced with augmenting Reynolds number ('Re') or concentration. The pressure drop (PD) intensified with the increased 'Re', along with the nano-fluid demonstrated a greater PD contrasted with the base fluid particularly at high 'Re'. The performance index, explicitly the ratio of HT rate to $\mathrm{PD}$, enhanced with the augmentation in 'Re' or concentration that was a propitious outcome. Thus, the performance index intended for the nano-fluid increased by nearly $142 \%$ by augmenting the 'Re' as of $1000-3000$.

Chao Ding et al [17], modeled LNG spiral wounds heat exchangers (SWHE). An explosion-proof experiment rig was implemented aimed at gauging HTC, in addition, scrutinizing flow patterns. The test part contained ' 3 '-layer tube packs to imitate the real structure along with flow setting of an SWHE. The experiment setting covered the heat fluxes $\left([4 \sim 10] \mathrm{kW} / \mathrm{m}^{2}\right)$, mass fluxes $\left([40 \sim 80] \mathrm{kg} / \mathrm{m}^{2} . \mathrm{s}\right)$ as well as vapor qualities $([0.2 \sim 1.0])$. The outcomes indicated, HTC primarily increased and after that lessened with the augmentation of vapor's quality, signifying a maximal at [0.8 0.9] vapor's quality; the heat flux's effect in HTC augmented with the augment of heat flux. Lastly, a cor-relation of HTC was formed encompassing ninety-eight (\%) data inside a deviation of \pm twenty (\%).

Leszek Malinowski and Jian-Hua Chen [18] introduced 3 fluid parallel channels HE with '3'-thermal communications. Partials differential equations were resulting for the HE. Centered upon the systematic solution formula, the steady states as well as the time to achieve it were resultant. The attained steady states time formula was confirmed via the numerical simulations. Additionally, it was required that the inputted function $u_{i}(t)$ is twofold incessantly differentiable that was sturdy in realistic application.

Iliya A. Radulov et al [19], formed the technique aimed at cold compaction of polymers-bonded $\mathrm{La}(\mathrm{Fe}, \mathrm{Mn}, \mathrm{Si}) 13 \mathrm{Hx}$ components which were appropriate for the forming of thinner plates. On account of the restricted samples' thickness, the quantity of magneto-caloric component (density) was critical for the magnetos caloric and also the mechanical features. Accordingly, the plates generated as of bi-modal powder mixtures had high flexural strength.

Simin Wang et al [20], posited SWHE centered on combining the Genetic Aggregation responses surface and also multi-objectives Genetic Algorithm (GA). The outcomes exhibited that the shell-side PD of the SWHE decreased with the augmentation in layer pitch, tube pitch along with winding angle. The shell-side HTC of the SWHE showed similar effect on layer pitch but it increased with the exterior tube's diameter. 3-optimum configurations were attained via the Multi-Object GA centered upon Genetic Aggregation responses surface. Contrasted to the original configurations, the average HTC of enhanced ones was improved via $2.93 \%$, even as the average PD was lessened by $40.27 \%$.

\section{MODELING PROCEDURES AND EXPERIMENTAL SETUP}

Here, SPHE is designed for the immiscible liquid-toliquid two-phased mixture. In general, liquid-gas along with liquid-vapor blends is utilized. But in this process, liquidliquid two-phase HT contemplates were directed in an SPHE with water - octane, kerosene, dodecane, diesel, and nitrobenzene. SPHE design engages ascertaining numerous flow variables as well as HT variables say PDs, equivalent diameters of flow channels as well as 'Re' of the 2-fluids flowing in the HE. In Figure 1, schematic design of the 
experiment's set-up is revealed.

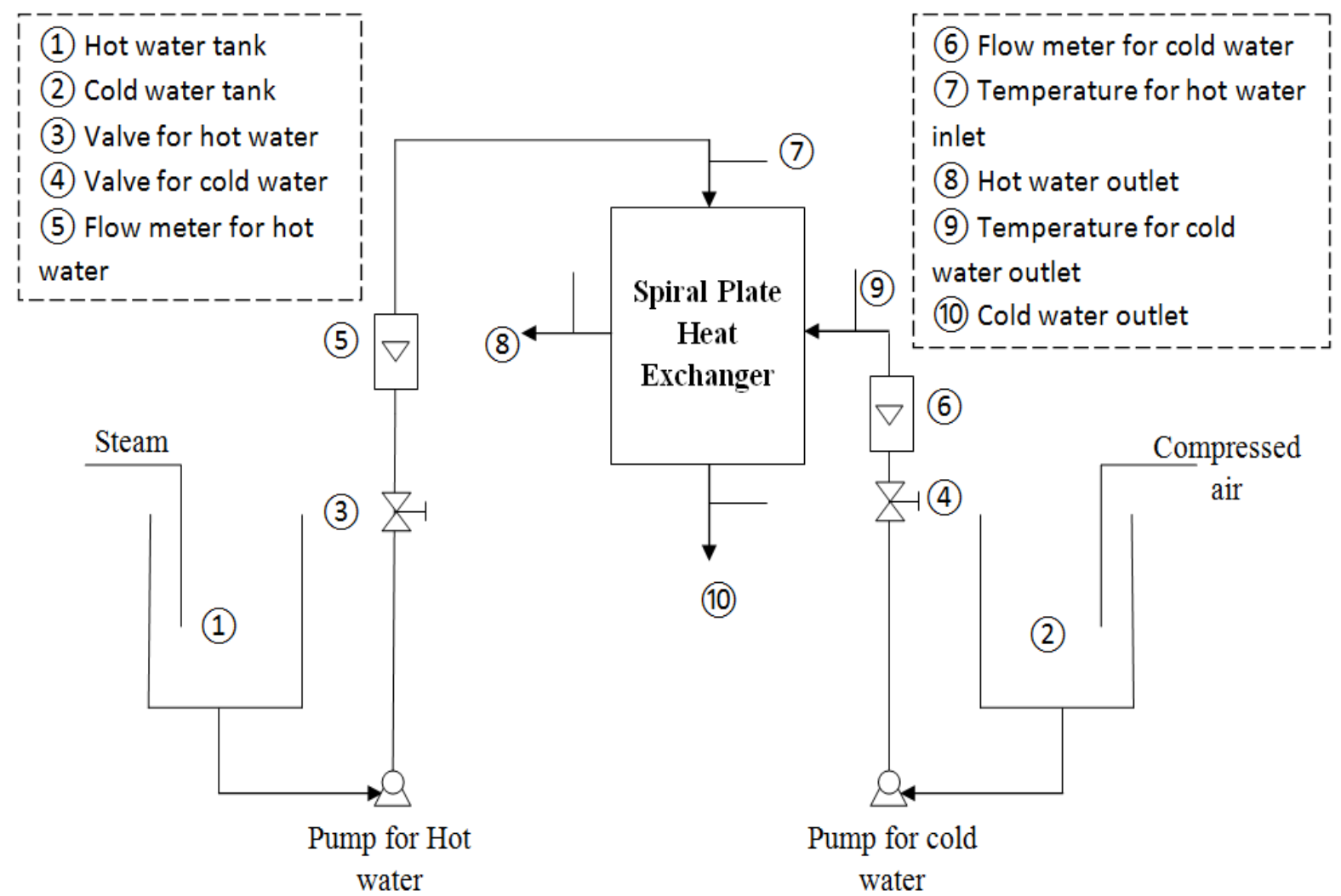

Figure1: Experimental setup in schematic way Representation

The HE utilized was an SPHE, manufactured via Alfa Lavals (India) Ltd., Pune, India. In this arrangement, the fluid utilized was hot in addition to cold water, which was heated on a vessel (stainless steel) via steam purging. To uphold the inlets' temperature to the HE for hot as well as cold water, a temperature regulator was utilized. The process fluid [cold-side] was amassed in different tanks, which were formed of stain-less steel. Weighed quantity of octane, nitrobenzene, kerosene, diesel, dodecane, as well as water was charged in to the tank for attaining the experiment gamut of immiscible liquid mass fractions. The agitation within the tank was upheld through air bubbling. Centrifugal pumps were utilized aimed at the circulation of the 2streams of fluids. The 2-phase rotary meters were attuned aimed at every experiment mass fraction previous to the experiment run. Online calibrated resistances temperature detectors encompassing digital indicators were utilized aimed at temperature gauges of the inlet along with outlet streams of the service as well as process fluids. The servicefluid-side inlets temperature together with the FR was held steady. The 2-phase side FR was diverse and for every chosen FR observations of all '4' temperatures and '2' FR were recorded subsequent to steady state was attained. The experiment runs with liquids (pure) on the process side were performed. The service together with the process fluid flow paths of $\mathrm{HE}$ is exhibited in Figure 2. The heat-transfer performance of the SPHEs mainly relies on mass FR of the fluid, flow region together with logarithmic temperature difference betwixt incoming and outgoing fluid streams.

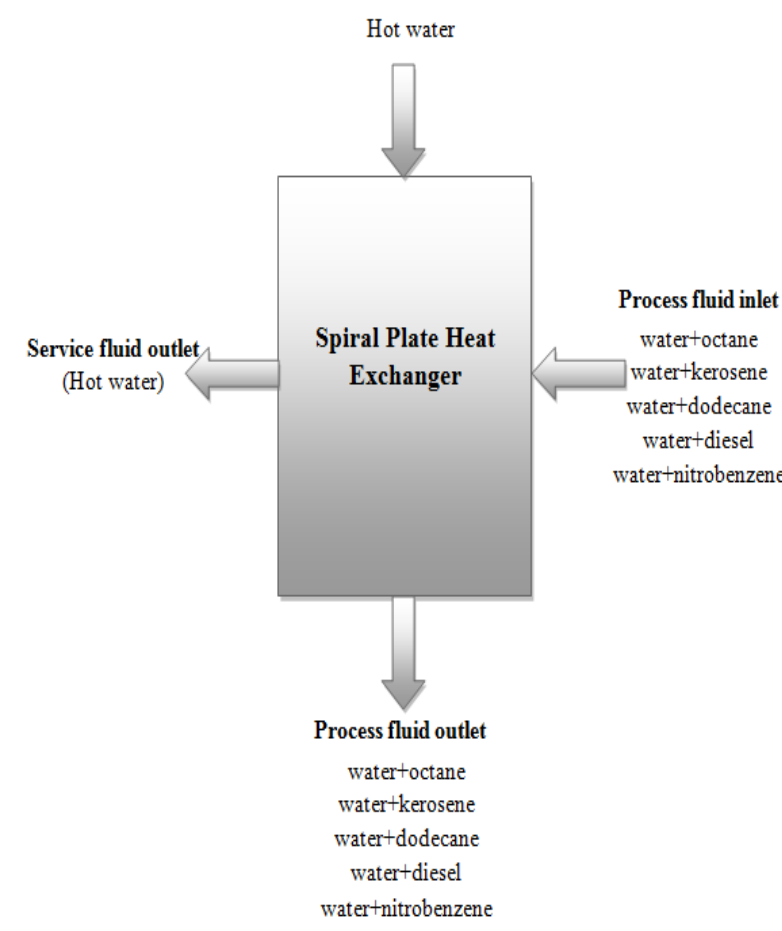

Figure 2: SPHE fluid flow paths

Published By: 


\section{An Experimental Access of Spiral Plate Heat Exchange Technique in Immiscible Liquid Mixtures}

\subsection{Heat Transfer Correlation Coefficient Calculation} Methods

\subsubsection{Over all heat transfer coefficients}

To find the over-all HTC, primarily heat load is gauged utilizing the below

$$
L=M_{h} S p_{h}(\Delta T)_{h}
$$

Where,

$M_{h}=$ Mass flow Rate of the Hot fluid $(\mathrm{kg} / \mathrm{s})$

$$
S p_{h}=\text { Hot fluid specific Heat }(J / k g K)
$$

\section{$(\Delta T)_{h}=$ Hot fluid Temperature $\operatorname{Drop}(K)$}

By utilizing the equation (1), the over-all HTC is obtained from the relation

$$
C=\frac{L}{A(\Delta T)_{l m}}
$$

Where,

$$
\mathrm{C}=\text { Overall Heat Transfer Coefficient }\left(\mathrm{W} / \mathrm{m}^{2} \mathrm{~K}\right)
$$

$$
\mathrm{A}=\text { Area Heat Transfer }\left(\mathrm{m}^{2}\right)
$$

$(\Delta \mathrm{T})_{\mathrm{lm}}=$ Logarithmi $\mathrm{c}$ mean Temperature difference $(\mathrm{K})$

\subsubsection{Nusselt number and heat transfer correlations}

Nusselt Number ( $\mathrm{Nu}$ ) helps to compute the hot-fluidside coefficient $\left(H_{h}\right)$ by utilizing

$$
N u=0.0315(\mathrm{Re})^{0.8}(p r)^{0.25}
$$

$\mathrm{Nu}$ is given below

$$
N u=\frac{H_{h} D_{e}}{K_{h}}
$$

Where,

$\mathrm{H}_{\mathrm{h}}=$ Heat transfer coefficient for $\operatorname{Hot}-\operatorname{side}\left(\mathrm{W} / \mathrm{m}^{2} \mathrm{~K}\right)$

$\mathrm{D}_{\mathrm{e}}=$ Equivalent diameter of the flow channel $(\mathrm{m})$

$$
\mathrm{K}_{\mathrm{h}}=\text { Hot fluid Thermal Conductivity }\left(\mathrm{W}(\mathrm{m} \mathrm{K})^{-1}\right)
$$

The cold- fluid -side or Two-phase side HTC $\left(H_{2 \Phi}\right)$ is calculated utilizing the expression, in which the results as of Equation (2) to (4) are utilized.

$$
\frac{1}{C}=\frac{1}{H_{h}}+\frac{t}{C_{s s}}+\frac{1}{H_{2 \Phi}}
$$

Where,

$\mathrm{t}=$ Wall thickness of of the spiral plate $(\mathrm{m})$

$$
\mathrm{C}_{\mathrm{ss}}=\text { Thermal conductivity of the wall }(\mathrm{W} / \mathrm{mK})
$$

$\mathrm{H}_{2 \Phi}=$ Two - phasefluid Heat transfer coefficient $\left(\mathrm{W} / \mathrm{m}^{2} \mathrm{~K}\right)$
The experiment $N u$ for the 2-phase CF is estimated centered on the 2-phase $\mathrm{CF}$ is evaluated centered upon the 2-phase heat-transfer co-efficient as of equation (5) utilizing the expression

$$
N u_{\text {exp erimental }}=\left(H_{2 \Phi}\right)_{\text {hotside }}\left(D_{e} / K\right)_{\text {coldside }}
$$

In forming a predictive correlation intended for the coldside 2-phase heat-transfer co-efficient, $H_{2 \Phi}, D_{e}, K_{2 \Phi}, \alpha_{2 \Phi}, \beta_{2 \Phi}, \gamma_{2 \Phi}, C p_{2 \Phi}$ and $X$ are the ' 8 ' relevant variables, presuming average properties allotted to the 2-phase system. There are '4' fundamental dimensions, so four dimensionless groups are involved in this process These are $\mathrm{Re}, N u$, Prandtl number $(\mathrm{Pr})$ and also the $X$ (mass fraction). Therefore, the common form of the correlations developed is

$$
N u_{\text {predicted }}=p(\operatorname{Re})^{q}(\operatorname{Pr})^{r}(X)^{s}
$$

Where, $p, q, r, s$ are constants, attained as of linear regression. The thermo physicals properties of the substances (pure) were computed centered upon the correlations. The 2-phase properties were attained utilizing linear mixing rules.

\section{RESULT AND DISCUSSION}

This section offers detailed experimental results to calculate the proposed SPHE features' performance from different aspects. The experimental settings are first presented, including the SPHE parameters and dimensions, specifications, Comparative Analysis, and Performance Analysis.

\subsection{Comparative Analysis}

The experimental configuration comprises of a 'SHE' attained as of Alfa Laval. It comprises RTD (resistances temperatures detectors), pumps, control valves, rota-meter, as well as tanks.

Table 1: SPHEs Parameters and Dimensions

\begin{tabular}{|c|c|c|}
\hline Details Of Exchangers & Units & Value \\
\hline Plate width & $\mathrm{m}$ & 0.3150 \\
\hline Plate Thickness & $\mathrm{m}$ & 0.0010 \\
\hline Flow length & $\mathrm{m}$ & 10.927 \\
\hline Mean Hydraulics Diameter & $\mathrm{m}$ & 0.0100 \\
\hline Mean Channels Spacing & $\mathrm{m}$ & 0.0050 \\
\hline Heat transfers area & $\mathrm{m}^{2}$ & 2.2400 \\
\hline
\end{tabular}

Dimension details of exchangers say plate width, plate thickness, Flow Length, Mean Hydraulic Diameter, Mean Channel Spacing, and HT area dimensions of the HE are exhibited in Table 1. 
Table 2: Specification of chemicals used to prepare Immiscible Liquid Mixtures

\begin{tabular}{|l|l|}
\hline Chemical & Specification Description \\
\hline Octane & $\begin{array}{l}\text { Octane is basically a hydrocarbon (HC) } \\
\text { as well as an alkane and is a element of } \\
\text { gasoline. }\left[\mathrm{C}_{8} \mathrm{H}_{18}\right] \text { is its chemical formula } \\
\text { and }\left[\mathrm{CH}_{3}\left(\mathrm{CH}_{2}\right)_{6} \mathrm{CH}_{3}\right] \text { is its condensed } \\
\text { structural one. Trimethylpentane is } \\
\text { utilized as the standard scores on the } \\
\text { octane rating scales. }\end{array}$ \\
\hline Kerosene stands as a mix up of 'HC' \\
The chemical composition relies on its \\
source however it typically comprises \\
almost ten disparate 'HC', each \\
encompassing 10 to 16 carbon atoms per \\
molecule. This property of kerosene \\
makes it a comparatively safer fuel to \\
stock and also to handle.
\end{tabular}

In Table 2 various chemical and their chemical descriptions are shown, immiscible liquids generally do not dissolved. In the proposed work, concentration is given on five chemicals like Octane, Kerozene, Dodecane, diesel, and nitrobenzene. These chemicals are mixed with water to form a non-miscible liquid mixture. The heating fluid utilized was de-mineralized water, heated on a stain-less steel vessel via steam injection, in addition, agitated to uphold a consistent temperature. The $\mathrm{CF}$ was amassed in a disparate stain-less steel tank. The weighted extent of the organic segment along with de-mineralized water was charged in to the tank to attain the experiment sort of mass fractions.
Table 3: Ranges of Reynolds and Prandtl Number

\begin{tabular}{|c|c|c|}
\hline System & $\operatorname{Re}$ & $\operatorname{Pr}$ \\
\hline Water & $168<\operatorname{Re}<447$ & $4.68<\operatorname{Pr}<5.64$ \\
\hline Octane + Water & $152<\operatorname{Re}<562$ & $4.98<\mathrm{P} \times 7.90$ \\
\hline Kerosene + Water & $171<\operatorname{Re}<473$ & $6.86<\mathrm{P}<51.61$ \\
\hline Dodecane + Water & $183<\operatorname{Re}<727$ & $5.49<\mathrm{P}<18.96$ \\
\hline Diesel + Water & $658<\operatorname{Re}<2098$ & $4.65<\operatorname{Pr}<6.54$ \\
\hline Nitrobenzene + Water & $819<\operatorname{Re}<2561$ & $6.59<\mathrm{P}<17.42$ \\
\hline
\end{tabular}

The 'Re' and also Prandtl Numbers' ranges are exhibited in Table 3. Aimed at 2-phase immiscible systems, 'Re' is centered upon the weighted-average thermo-physical features of the fluids at the relevant mean bulk temperatures. The attained data are set by means of regression to the correlation, Close to observations taken as of the other works; correlations are not developed aimed at the fluids, which were consistently bad at illustrating the experiment's data. Deviations ranged as of \pm twenty-five (\%) to orders of magnitude. The entire systems studied brought about a bad fit even an effort at inferring one correlation. Centered upon the studies together with other published outcomes, it seems that the HTC in LL-2-phase systems relies considerably on the chosen organic phase's nature.

Table 4: Average physical properties of $\mathrm{HF}$ and $\mathrm{CF}$

\begin{tabular}{|l|l|l|l|}
\hline $\begin{array}{l}\text { Physical } \\
\text { Properties }\end{array}$ & Units & Cold Fluid & Hot Fluid \\
\hline Plate spacing & $\mathrm{m}$ & 0.0317 & 0.0059 \\
\hline $\begin{array}{l}\text { Internal } \\
\text { diameter }\end{array}$ & $\mathrm{m}$ & 0.03049 & 0.03049 \\
\hline Density & $\mathrm{Kg} / \mathrm{m}^{3}$ & 1348.59 & 999.58 \\
\hline Plate thickness & $\mathrm{m}$ & 0.0034 & 0.0034 \\
\hline $\begin{array}{l}\text { Thermal } \\
\text { conductivity }\end{array}$ & $\mathrm{W} / \mathrm{m} \mathrm{K}$ & 0.6233 & 0.5916 \\
\hline Heat capacity & $\mathrm{J} / \mathrm{kg} \mathrm{K}$ & 3768.14 & 4196.70 \\
\hline $\mathrm{T}_{\text {out }}$ & $\mathrm{K}$ & 297.15 & 284.88 \\
\hline $\mathrm{T}_{\text {in }}$ & $\mathrm{K}$ & 298.60 & 283.14 \\
\hline Mass flow rate & $\mathrm{Kg} / \mathrm{s}$ & 128.68 & 19.81 \\
\hline
\end{tabular}

Table 4 tabularized the average thermo-physics properties of the fluids utilized here. As contrasted with the case study, augmentation on PD on hot as well as the cold side is rooted via the substantial augment of the mean velocity of the working fluids on all sides. Moreover, this velocity augment begets a noticeable rise on HTCs of hot along with cold sides that ameliorates the HT mechanism via augmenting overall HTC values. In contrast, an augment in HT begets a considerable rise in the complete cost of ' $\mathrm{HE}$ ' on account of the effect of notable augment in PD rates.

Table 5: Octane, Kerosene, Dodecane, Nitrobenzene, Diesel- Water system Statistical Analysis

\begin{tabular}{|c|c|c|c|c|c|c|c|c|c|}
\hline \multirow{2}{*}{$\begin{array}{l}\text { S. } \\
\text { No }\end{array}$} & \multirow[t]{2}{*}{ System } & \multicolumn{4}{|c|}{ P-Values } & \multirow[t]{2}{*}{$\mathbf{R}^{2}$} & \multirow[t]{2}{*}{$\mathrm{S}$} & \multirow[t]{2}{*}{$\mathrm{n}$} & \multirow[t]{2}{*}{$\sigma$} \\
\hline & & a & b & c & d & & & & \\
\hline 1 & $\begin{array}{c}\text { Octane + } \\
\text { Water }\end{array}$ & $\begin{array}{c}8.19 \mathrm{E}- \\
24\end{array}$ & $\begin{array}{c}1.27 \mathrm{E}- \\
24\end{array}$ & $\begin{array}{c}1.06 \mathrm{E}- \\
05\end{array}$ & $\begin{array}{c}1.06 \mathrm{E}- \\
06\end{array}$ & 0.9800 & 0.1008 & 35 & 0.5966 \\
\hline 2 & $\begin{array}{c}\text { Kerosene + } \\
\text { Water }\end{array}$ & $\begin{array}{c}1.34 \mathrm{E}- \\
27\end{array}$ & $\begin{array}{c}8.94 \mathrm{E}- \\
30\end{array}$ & $\begin{array}{c}1.50 \mathrm{E}- \\
13\end{array}$ & $\begin{array}{l}3.89 \mathrm{E}- \\
12\end{array}$ & 0.9862 & 0.0745 & 35 & 0.4407 \\
\hline 3 & $\begin{array}{c}\text { Dodecane + } \\
\text { Water }\end{array}$ & $\begin{array}{c}1.49 \mathrm{E}- \\
18\end{array}$ & $\begin{array}{c}1.88 \mathrm{E}- \\
18\end{array}$ & $\begin{array}{c}1.88 \mathrm{E}- \\
22\end{array}$ & 0.0098 & 0.9365 & 0.2103 & 39 & 1.3134 \\
\hline 4 & $\begin{array}{c}\text { Nitrobenzene } \\
\text { + Water }\end{array}$ & $\begin{array}{c}4.29 \mathrm{E}- \\
6\end{array}$ & $\begin{array}{c}3.25 \mathrm{E}- \\
6\end{array}$ & $4.7 \mathrm{E}-6$ & $2.89 \mathrm{E}-6$ & 0.919 & 0.122 & 35 & 0.569 \\
\hline 5 & $\begin{array}{c}\text { Diesel + } \\
\text { Water }\end{array}$ & $\begin{array}{c}1.88 \mathrm{E}- \\
23\end{array}$ & $\begin{array}{c}1.50 \mathrm{E}- \\
25\end{array}$ & $\begin{array}{c}1.99 \mathrm{E}- \\
7\end{array}$ & 0.14212 & 0.981 & 0.0969 & 34 & 0.565 \\
\hline
\end{tabular}




\section{An Experimental Access of Spiral Plate Heat Exchange Technique in Immiscible Liquid Mixtures}

Table 5 exhibits the statistical scrutiny of the proposed work. It aids to infer the predictive empirical correlations intended for HT on 2-phase LL structures that encompass value on the sizing of exchangers aimed at managing 2phase liquid mixtures. Aimed at this cause, the data were well-fitted via regression. Table 5 proffers the values attained for a to $\mathrm{d}$. The statistic scrutiny was done for testing the regression. Each system comprises 0.980, 0.9862, 0.9365 , 0.919, along with, 0.981 of R2 values correspondingly. Standard errors were tiny. The statistic implication of the co-efficients was experienced via evaluating the P-values (i.e. the functional form selected was apt). The scrutiny illustrated that the residuals complied with a normal distribution. Nevertheless, since the $\mathrm{R}^{2}$ of the fit is higher, its correlation might be still utilized in a predictive way. The outcomes of the entire ' 5 ' systems are amassed in Table 5. The correlations developed were after that tested in opposition to novel experiential data in the same (5) systems. The gauged values centered upon these $\left(H_{2 \Phi}\right)$ constants agree with the experimentation data within an error of \pm fifteen $(\%)$.

\subsection{Performance Analysis}

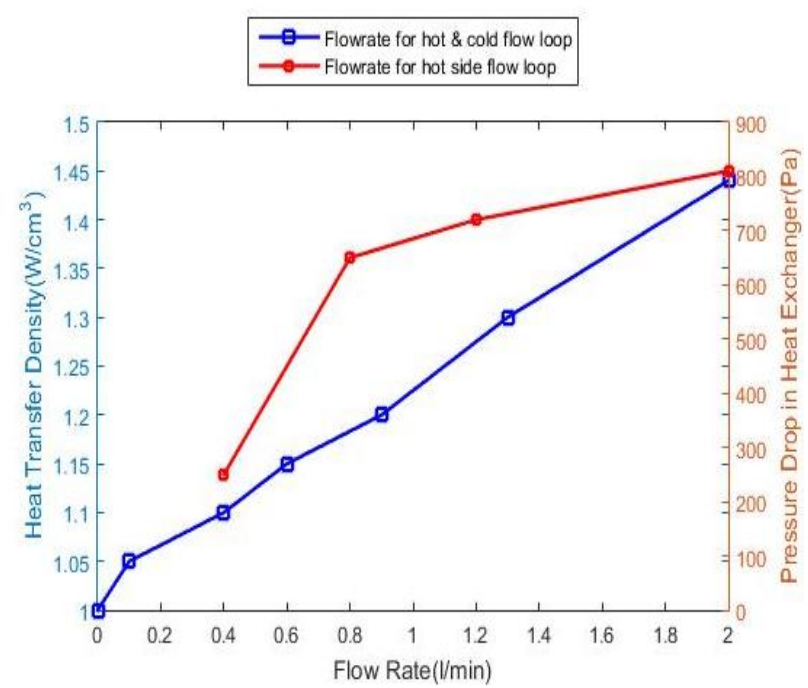

Figure 3: Variation of the heat transfer density and PD corresponding to FR

The difference of the HT density with liquid FR is exhibited in Figure 3. The HT density that alludes to the quantity of heat per unit volume transported via the $\mathrm{HE}$ is extorted to calculate the thermal efficacy of the $\mathrm{HE}$ concerned. Besides the HT density, the PD on the HE, particularly on the hot side loop in which the mini pump is incorporated, is as well significant to the cooling system. Low PD is ideally in reality to lessen the pump power. The difference of the PD with the FR is also displayed in Figure 3. In this instance, the FR in the hot flow loops as well as cold flow loop stays the same. Inevitably, the PD in the HE augments with an augment in the FR.

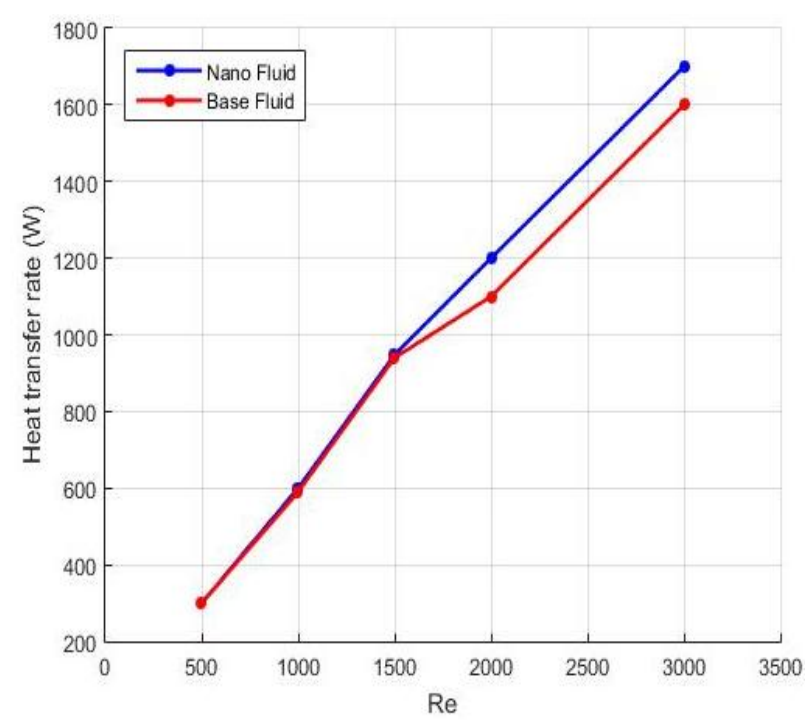

Figure 4: HT rate in SPHE

HT rate in SPHE is exhibited in Figure 4. HT rate possesses a thermal conductivity that ameliorates the heat transfer on the fluid. Obviously, the impact of summing the particles is more extreme at high 'Re'. Here HF and CF play an imperative role in changing the HT in 'HE'. The existence of HF side has no noteworthy impact on the HT rate at lower 'Re', whilst this effect turns into vital with the 'Re' augmentation.

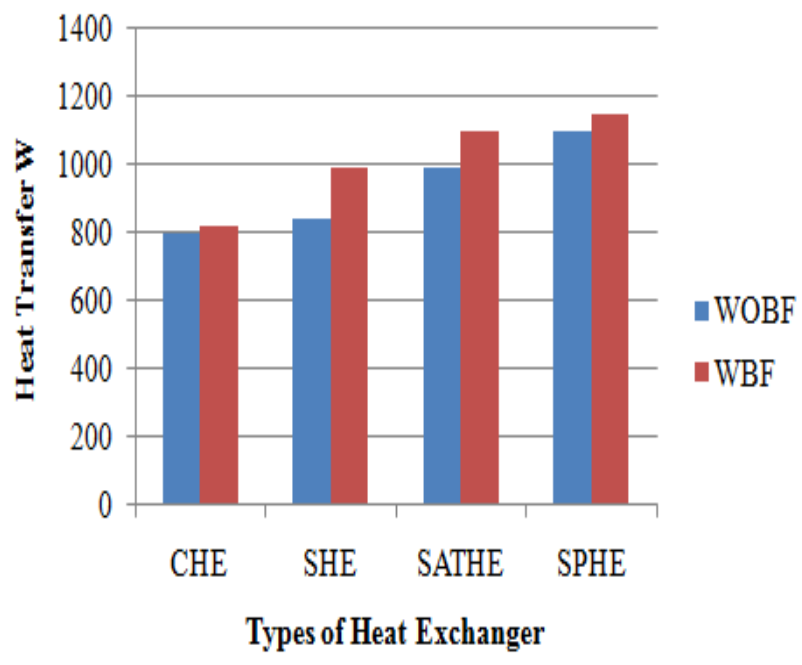

Figure 5: Comparision graph for different types of heat exchanger Vs Heat Transfer Corresponding to Base fluids

Figure 5 exhibits a general comparative scrutiny betwixt the ' 4 ' HE with and without the adding up of the base fluids. Aimed at this comparison, SHE, Concentric Heat Exchanger (CHE), Shell and Tube Heat Exchanger (SATHE) as well as SPHE are regarded with and with-out Base fluid. It is described that the SPHE proffers the uppermost heat flux on account of its high HT surface region to volume ratio when weighted against the entire other configurations. 


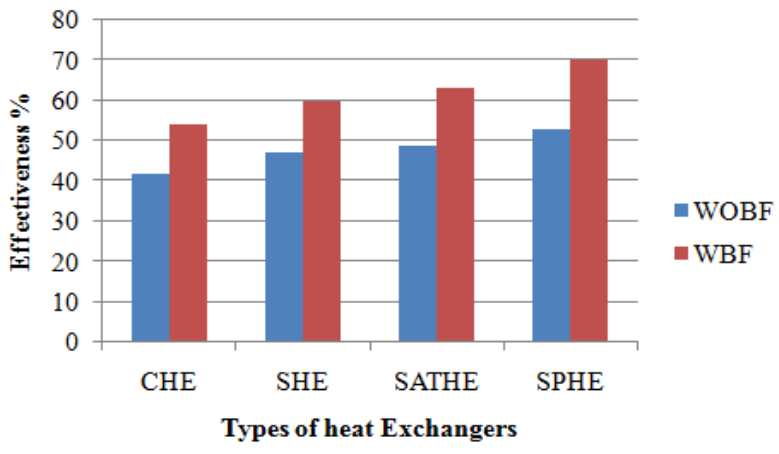

Figure 6: Comparision graph for different types of HE and their Effectiveness corresponding to Base fluids

In this section, a general comparative scrutiny betwixt all of the ' 4 ' HEs with and without the addition of the Base fluids is shown. Figure 6 displays this study with and without utilizing Base fluids for all ' 4 ' kinds of HE such that CHE, SHE, SATHE and SPHE. It produces that the SPHE offers the highest effectiveness value.

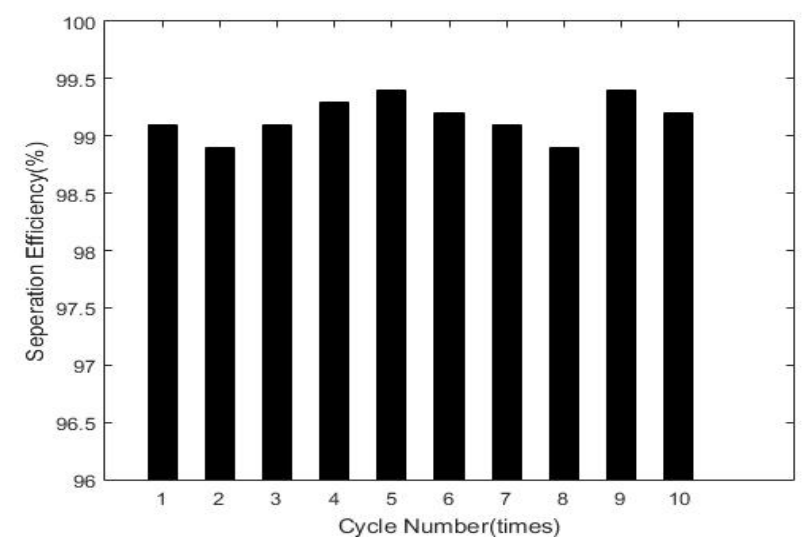

Figure 7: The separation efficiency with cycle numbers

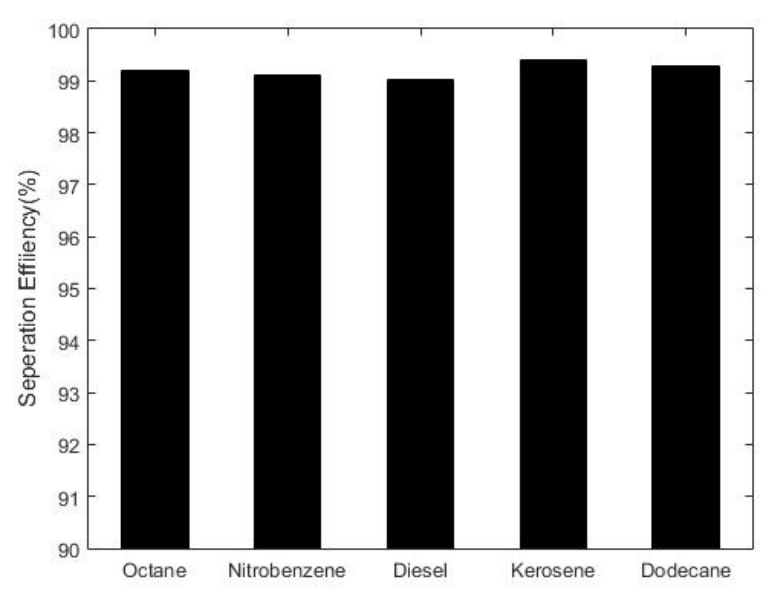

Figure 8: The separation efficiency with Immiscible mixture

In Figures $7 \& 8$, separation efficiency and also the number of cycles essential for the separation is plotted. The separation efficiency of Octane, Kerosene, Dodecane, Nitrobenzene, and Diesel are represented in respects of Percentage. Generally, in Immiscible liquid mixture, separation efficiency is computed to determine stable performance and Heat Resistance.

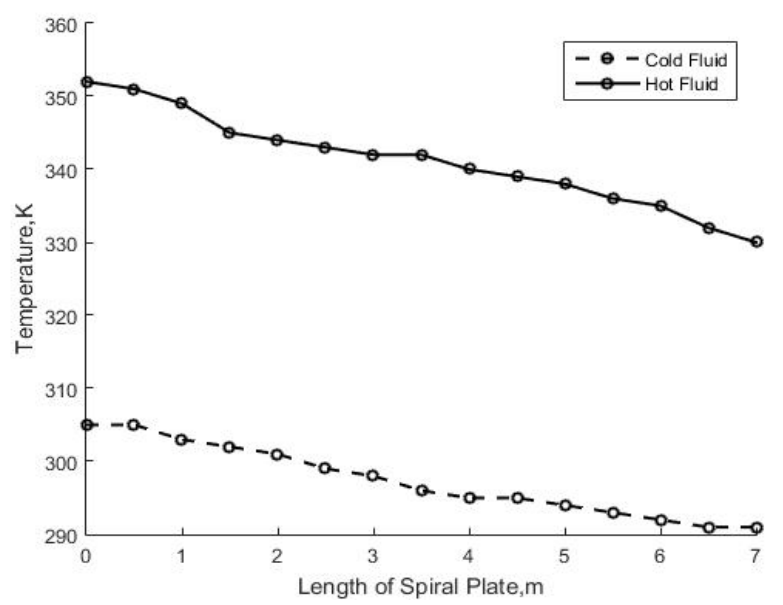

Figure 9: HF and CF Temperature Variation (K)

Figure 9 depicts the temperature variation of $\mathrm{HF}$ and $\mathrm{CF}$ according to the Length of the Spiral Plate. An SPHE is modeled to account for the fluid flow together with HT characteristics under the particular $\mathrm{HF}$ and $\mathrm{CF}$ flow rates. The $T_{\text {in }}$ of CF and HF are maintained constant, and also the $\mathrm{T}_{\text {out }}$ for the HF and CFs are calculated for counterflow configurations. A data of temperatures together with HTC at a range of locations down the plates' length are extorted. It is observed from Figure 9, that the $\mathrm{HF}$ temperature decreases and CF temperature augments along the length of the SPHE.

\section{CONCLUSION}

This paper offers experiment data as of the measurement of the HTC of an Immiscible mixture of Water- octane, Nitrobenzene, Kerosene, Dodecane, along with Diesel mixture on an SPHE. The attained data as of the investigational study are contrasted with various sorts of HEs. Centered upon the inlet together with $\mathrm{T}_{\text {out }}$ as well as FR of the hot along with the cold streams, HTCs were evaluated and novel correlations aimed at LL-2-phase HT were made, as an extra function of the composition of the mix. Novel correlations are proposed centered upon the experiment data that might be utilized aimed at practical applications. Regression scrutiny was done, and also it is observed that the correlations loyally reproduce the variations perceived on the experiments. The developed correlation envisages the experimental HT behavior with-in \pm fifteen (\%). These aspects bring about better design capability intended for compact HE handling liquid-liquid '2'-phase immiscible mixtures.

\section{REFERENCES}

1. Ali Karimi, and Masoud Afrand, "Numerical study on thermal performance of an air-cooled heat exchanger: Effects of hybrid nanofluid, pipe arrangement and cross section”, Energy Conversion and Management, vol. 164, pp. 615-628, 2018.

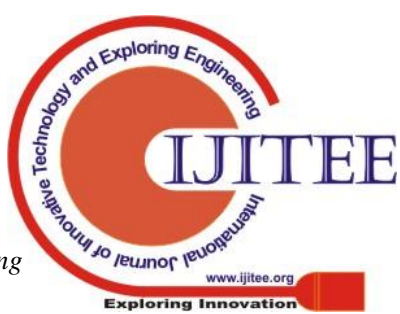


2. Emerson Hochsteiner de Vasconcelos Segundo, Viviana Cocco Mariani, and Leandro dos Santos Coelho, "Design of spiral heat exchanger from economic and thermal point of view using a tuned wind-driven optimizer", Journal of the Brazilian Society of Mechanical Sciences and Engineering, vol. 40, no. 4, pp. 212, 2018.

3. Jianfeng Huang, Guohua Chen, Lei Shu, Yuanfang Chen, and $\mathrm{Yu}$ Zhang, "Impact of fouling on flow-induced vibration characteristics in fluid-conveying pipelines", IEEE Access, vol. 4, pp. 6631-6644, 2016.

4. Detlef Lohse, "Towards controlled liquid-liquid microextraction", Journal of Fluid Mechanics, vol. 804, pp. 1-4, 2016

5. Éric V. Sempels, and Frédéric J. Lesage, "Optimal thermal conditions for maximum power generation when operating thermoelectric liquid-to-liquid generators", IEEE Transactions on Components, Packaging and Manufacturing Technology, vol. 7, no. 6, pp. 872-881, 2017.

6. Eric V. Sempels, and Frédéric J. Lesage, "Optimization of thermoelectric generators in the presence of heat losses and fluid flows", IEEE Transactions on Components, Packaging and Manufacturing Technology, vol. 8, no. 9, pp. 1573-1580, 2018.

7. Rasikh Tariq, Kamran Afaq Sheikh, and Muhammad Shayyan, "Study of thermal performance of common heat exchangers by using nanofluids", In 2018 International Conference on Applied and Engineering Mathematics (ICAEM), pp. 130-135. IEEE, 2018.

8. Oğuz Emrah Turgut, and Mustafa Turhan Çoban, "Thermal design of spiral heat exchangers and heat pipes through global best algorithm", Heat and Mass Transfer, vol. 53, no. 3, pp. 899-916, 2017.

9. Kavadiki Veerabhadrappa, Gulabal Vinayakaraddy, K. N. Seetharamu, Pradeep G. Hegde, and V. Krishna, "Transient behavior of three-fluid heat exchanger with three thermal communications under step change in inlet temperature of fluids using finite element method", Applied Thermal Engineering, vol. 108, pp. 1390-1400, 2016.

10. Sapna Gupta, Rajeev Gupta, and Subhransu Padhee, "Parametric system identification and robust controller design for liquid-liquid heat exchanger system", IET Control Theory \& Applications, vol. 12, no. 10, pp. 1474-1482, 2018.

11. Ryohei Fujii, Mingcong Deng, and Shin Wakitani, "Nonlinear remote temperature control of a spiral plate heat exchanger", In 2015 International Conference on Advanced Mechatronic Systems (ICAMechS), pp. 542547. IEEE, 2015.

12. Vladimir Chirkov, Ekaterina Rodikova, and Yury Stishkov, "The dependence of the efficiency of electrohydrodynamic heat exchanger on the electric conductivity of liquid", IEEE Transactions on Industry Applications, vol. 53, no. 3, pp. 2440-2445, 2017.

13. Miguel A. Caro, Tomi Laurila, and Olga LopezAcevedo, "Accurate schemes for calculation of thermodynamic properties of liquid mixtures from molecular dynamics simulations", The Journal of Chemical Physics, vol. 145, no. 24, pp. 244504, 2016.

14. Gongyue Tang, Yong Han, Boon Long Lau, Xiaowu Zhang, and Daniel Min Woo Rhee, "Development of a compact and efficient liquid cooling system with silicon microcooler for high-power microelectronic devices", IEEE Transactions on Components, Packaging and Manufacturing Technology, vol. 6, no. 5, pp. 729-739, 2016.

15. Manabu Aoki, "Vertically layered heat exchanger for the solid nitrogen heat capacitor cooling high-temperature superconducting magnet”, IEEE Transactions on Applied Superconductivity, vol. 26, no. 2, pp. 1-4, 2016.
16. Mehdi Bahiraei, Hamid Kiani Salmi, and Mohammad Reza Safaei, "Effect of employing a new biological nanofluid containing functionalized graphene nanoplatelets on thermal and hydraulic characteristics of a spiral heat exchanger", Energy Conversion and Management, vol. 180, pp. 72-82, 2019.

17. Chao Ding, Haitao Hu, Guoliang Ding, Jie Chen, Xiaoguang Mi, Sicong Yu, Jianrui Li, "Experimental investigation on downward flow boiling heat transfer characteristics of propane in shell side of LNG spiral wound heat exchanger", International Journal of Refrigeration, 2017.

18. Leszek Malinowski, and Jian-Hua Chen, "Analytical solutions of the equations for the transient temperature field in the three-fluid parallel-channel heat exchanger with three thermal communications", International Journal of Heat and Mass Transfer, vol. 96, pp. 164-170, 2016.

19. Iliya A. Radulov, Konstantin P. Skokov, Dmitriy Yu Karpenkov, Tobias Braun, and Oliver Gutfleisch, "Polymer-bonded $\mathrm{La}$ (Fe, Mn, Si) $13 \mathrm{H}$ x plates for heat exchangers", IEEE Transactions on Magnetics, vol. 51, no. 11, pp. $1-4,2015$

20. Wang S., G. Jian, J. Xiao, J. Wen, Z. Zhang, "Optimization investigation on configuration parameters of spiral-wound heat exchanger using genetic aggregation response surface and multi-objective genetic algorithm", Applied Thermal Engineering, 2017.

\section{AUTHORS BIOGRAPHY}

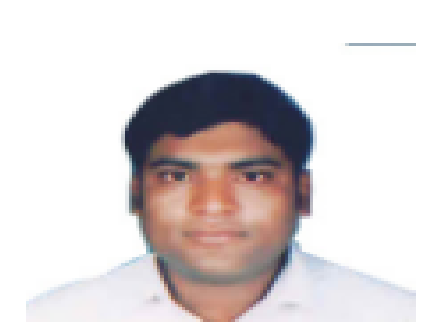

Bhanu Pratap Pulla currently Ph.D scholar in the college of Mechanical Engineering Department, Sri Sai university of Technology and Medical Science Sehore, Madhya Pradesh. His research interests includes Thermal Engineering and Heat Transfer.

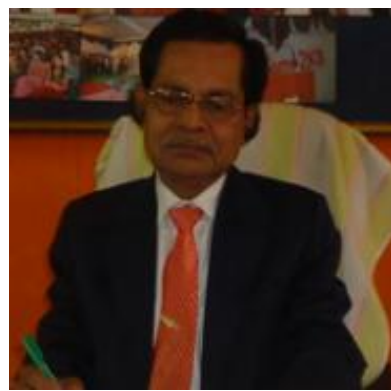

Dr. G. R. Selokar (Supervisor) received the ph.D degree from BHU (Banarus Hindu University) he is currently professor in Mechanical Engineering Department and also registrar for Sri Satya Sai University of Technology and medical sciences Sehore, Madhya Pradesh. His research interests includes Thermal Engineering and Heat Transfer. 